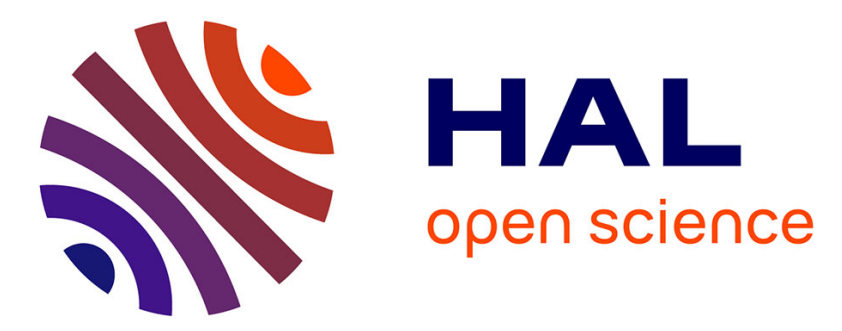

\title{
Optimizing Fuel Consumption and Pollutant Emissions of a Spark Ignition Engine for Eco-driving Applications
}

Alice Guille Des Buttes, Bruno Jeanneret, Alan Keromnes, Serge Pelissier, Luis Le Moyne

\section{- To cite this version:}

Alice Guille Des Buttes, Bruno Jeanneret, Alan Keromnes, Serge Pelissier, Luis Le Moyne. Optimizing Fuel Consumption and Pollutant Emissions of a Spark Ignition Engine for Eco-driving Applications. VPPC 2018, Vehicle Power and Propulsion Conference, Aug 2018, Chicago, United States. hal$02013962 \mathrm{v} 2$

\section{HAL Id: hal-02013962 \\ https://hal.science/hal-02013962v2}

Submitted on 14 Apr 2021

HAL is a multi-disciplinary open access archive for the deposit and dissemination of scientific research documents, whether they are published or not. The documents may come from teaching and research institutions in France or abroad, or from public or private research centers.
L'archive ouverte pluridisciplinaire HAL, est destinée au dépôt et à la diffusion de documents scientifiques de niveau recherche, publiés ou non, émanant des établissements d'enseignement et de recherche français ou étrangers, des laboratoires publics ou privés. 


\title{
Optimizing Fuel Consumption and Pollutant Emissions of a Spark Ignition Engine for Eco-driving Applications
}

\author{
Alice Guille des Buttes*, Bruno Jeanneret*, Alan Keromnes ${ }^{\dagger}$, Serge Pelissier* and Luis Le Moyne ${ }^{\dagger}$ \\ * Univ. Lyon, IFSTTAR, AME, LTE F-69675, Lyon, France \\ Email: alice.guille-des-buttes@ifsttar.fr,bruno.jeanneret@ifsttar.fr \\ $\dagger$ DRIVE EA1859, Univ. Bourgogne - Franche Comte, 49 rue Mademoiselle Bourgeois, Nevers, France
}

\begin{abstract}
The transportation sector is a major contributor to both air pollution and greenhouse gas emissions. While optimizing fuel consumption reduces $\mathrm{CO} 2$ emissions, it can increase fuel-rich operation and cause higher $\mathrm{HC}$ and $\mathrm{CO}$ emissions. A simplified emissions model is thus introduced in order to account for the impact of air/fuel ratio on both the exhaust concentration of regulated pollutants and the catalyst efficiency. This model is used to solve the eco-driving problem with dynamic programming and a weighted objective function. An emission-centered and a consumption-centered scenario are compared on various driving cycles and with several time constraints. The optimal driving style in terms of emissions shows a substantial decrease in $\mathrm{CO}$ and HC while consumption stays relatively stable and NOx emissions slightly increase.
\end{abstract}

Index Terms-eco-driving, pollutant emissions, dynamic programming, air/fuel ratio

\section{INTRODUCTION}

The transportation sector is a major contributor to both air pollution and greenhouse gas emissions. Researchers and manufacturers have thus been working on the design of vehicle components to improve their aftertreatment capabilities and energy efficiency. For a given design, emission levels and fuel consumption still vary across the operating range [1]. Therefore, the vehicle's performance strongly depends on the driver's choice of gears and speed trajectory [2]. Ecodriving attempts to determine the optimal driving style for a specific vehicle on a predefined trip.

Many publications on ecodriving focus on minimizing fuel consumption, which is proportional to $\mathrm{CO}_{2}$ emissions. However, previous work by Mensing [3] showed that such strategies can increase other pollutant emissions because they encourage the use of high engine loads. To address the tradeoff between emissions and consumption, Mensing reduced operation in this unfavorable region by introducing an arbitrary penalty factor. Johansson also recommended avoiding highload areas in an experimental study on ecodriving style [4].

The aim of our work is to provide a more systematic approach to this optimization problem by including a simplified emissions model in an ecodriving method based on dynamic programming.

The following section introduces the model used to evaluate the impact of air/fuel ratio (AFR) on exhaust composition and catalytic converter efficiency in high-load ranges. Next,

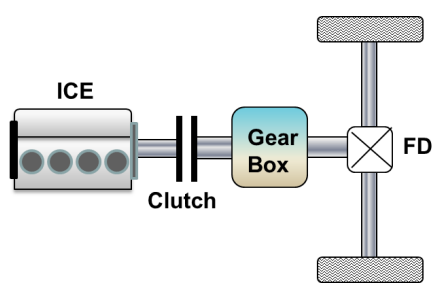

Fig. 1. Standard powertrain schematic

the optimal driving style for a given trip is determined with dynamic programming. Finally, the resulting trade-off between fuel consumption and emissions is discussed.

\section{MODELS}

\section{A. Vehicle model}

This work focuses on the behavior of spark ignition engines. The engine is studied in the context of a standard powertrain, which includes an internal combustion engine (ICE), followed by a clutch, a gearbox, and a final drive reduction (FD), as seen in Fig. 1.

The vehicle's motion is modeled on the longitudinal axis, where the projection of Newton's second law (1) expresses the relation between the powertrain's traction force $\left(F_{t}\right)$, the aerodynamic drag $\left(F_{\text {aero }}\right)$, the rolling resistance $\left(F_{\text {roll }}\right)$ and the acceleration force given by the mass of the vehicle $(m)$, the equivalent mass of the rotating parts $\left(m_{\text {rot }}\right)$, and the acceleration $(a)$.

$$
F_{t}=\left(m+m_{\text {rot }}\right) \cdot a+F_{\text {aero }}+F_{\text {roll }}
$$

The aerodynamic drag given by (2) is proportional to the air density $(\rho)$, the body's cross sectional area $(A)$ and drag coefficient $\left(C_{D}\right)$ and the square speed of the vehicle $(v)$.

$$
F_{\text {aero }}=\frac{1}{2} \cdot \rho \cdot A \cdot C_{D} \cdot v^{2}
$$

The rolling resistance is given by (3) where $g$ is the standard acceleration due to gravity, $c_{0}$ the constant rolling resistance coefficient, and $c_{1}$ is the quadratic rolling resistance coefficient.

$$
F_{\text {roll }}=m \cdot g \cdot\left(c_{0}+c_{1} \cdot v^{2}\right)
$$




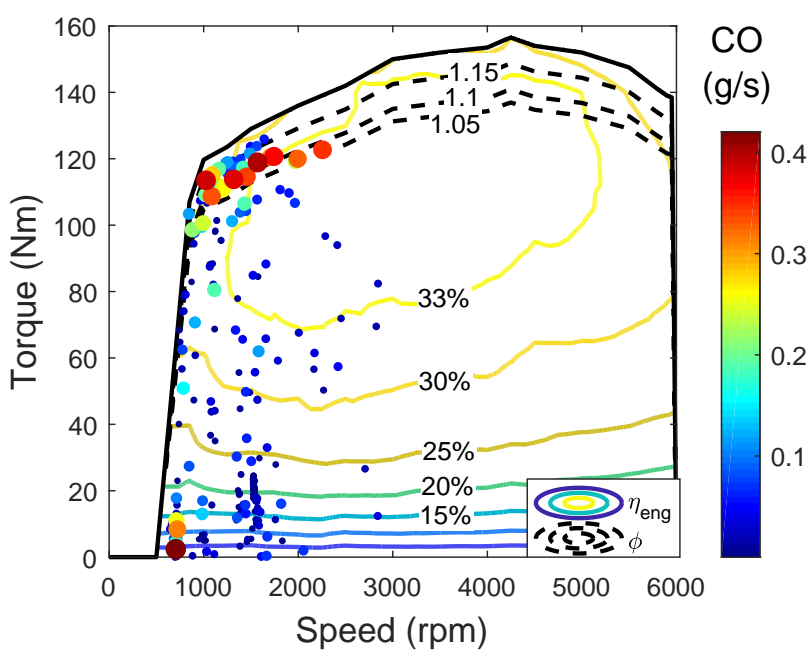

Fig. 2. Engine efficiency and CO emissions (measures) - AFR (model)

The transmission is composed of a final drive (with a ratio $k_{F D}$ and an efficiency $\eta_{F D}$ ) and a gearbox (with a ratio $k_{G B}$ and an efficiency $\eta_{G B}$ ). Equation (4) expresses the engine's torque $\left(T_{e n g}\right)$ as a function of the transmission parameters, the traction force and the tire radius $\left(R_{\text {tire }}\right)$.

$$
T_{\text {eng }}=F_{t} \cdot \frac{R_{\text {tire }}}{\eta_{F D} k_{F D} \cdot \eta_{G B} k_{G B}}
$$

In order to identify the engine's operating point, the engine speed $\left(\omega_{\text {eng }}\right)$ also has to be defined as given by (5).

$$
\omega_{\text {eng }}=v \cdot \frac{k_{F D} \cdot k_{G B}}{R_{\text {tire }}}
$$

\section{B. Spark ignition engine}

1) Fuel consumption: knowing the engine's operating point (see vehicle models) and assuming a quasi-static relationship, the fuel consumption $\left(\dot{m}_{f}\right)$ can be computed from a lookup table, as expressed in (6). The table is obtained from test-bench measurements on a 1.6-liter gasoline indirect injection engine and the corresponding engine efficiency is shown as map of speed and torque (Fig. 2).

$$
\dot{m}_{f}=\dot{m}_{f}\left(\omega_{e n g}, T_{e n g}\right)
$$

It can be observed on the map (Fig. 2) that in the low-load ranges, efficiency increases with torque as the relative weight of friction decreases. However, efficiency decreases again in high-load ranges (contour lines closing on themselves). This phenomenon coincides with the high emissions measured by Mensing on an ecodriving cycle in [3], which appear as red dots in Fig. 2. This can be attributed to a change in the chemical composition of the air/fuel mixture.

In gasoline engines, fuel can be injected in excess with respect to the stoichiometric combustion ratio in high-load ranges [5]. This has several advantages: as fuel vaporization lowers the gas temperature at intake, it increases its density
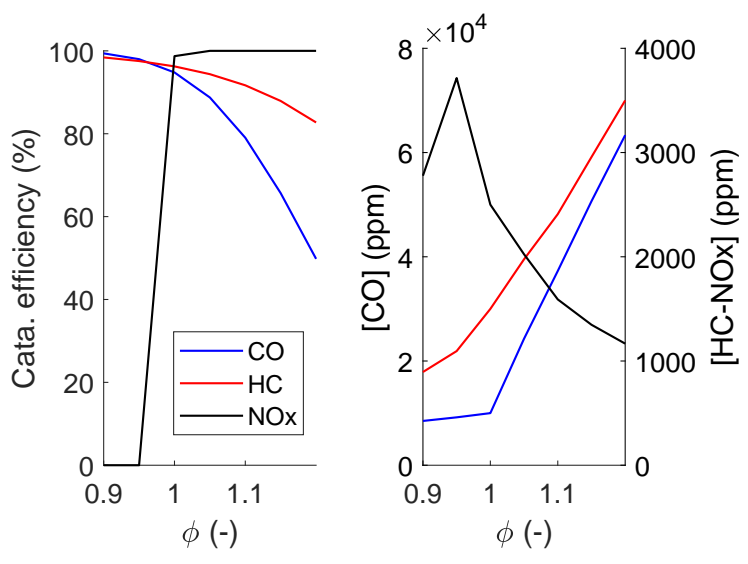

Fig. 3. Data input for the emissions model

and draws a higher mass of mixture in the cylinder. Fuelrich conditions also decrease the exhaust temperature, lowering stress on the engine [6]. However, this strategy causes incomplete combustions, which are detrimental to the overall energy efficiency and lead to unburned hydrocarbons (HC) and $\mathrm{CO}$ emissions.

2) AFR and pollutant emissions: in this paper, we assume that the mixture is stoichiometric up to $85 \%$ of the maximum torque, as it is the limit of the high-emissions zone identified in [3]. The relative AFR $(\phi)$ then increases with the load. It can be expressed as a static function of the engine speed and torque (7). The corresponding map for the relative AFR is shown in dashed lines in Fig. 2. The quasi-static approach assumes that the engine's AFR control compensates for transients due to fuel pooling in the intake manifold.

$$
\phi=\phi\left(\omega_{\text {eng }}, T_{\text {eng }}\right)
$$

The pollutant concentrations ( $[S]$ with $S=\mathrm{CO}, \mathrm{HC}, \mathrm{NOx}$ ) before the catalyst are then interpolated based on typical values of the AFR for spark ignition engines as in [6] (see Fig. 3). Each pollutant's mass flow $\left(\dot{m}_{S}\right)$ is given by (8). It depends on the concentration of the respective species and the flow of gas out of the engine $\left(\dot{m}_{g}\right)$. As the composition of the mixture is given by the AFR, the flow of gas can be determined from the fuel consumption, the relative AFR and the stoichiometric $\operatorname{AFR}\left(\psi_{S}\right)$.

$$
\dot{m}_{S}=\dot{m}_{g} \cdot[S](\phi)=\dot{m}_{f} \cdot\left(1+\frac{\psi_{S}}{\phi}\right) \cdot[S](\phi)
$$

Finally, tailpipe emissions strongly depend on the threeway catalyst, which removes more than $90 \%$ of the regulated pollutants in its nominal working conditions: stoichiometric AFR and above light-off temperature [7]. Since our study focuses on the influence of the AFR in high-load ranges, we assume perfect thermal efficiency. The capacity of the catalyst to store oxygen in order to maintain stoichiometric AFR in the short term is also neglected. The catalyst efficiency $\left(\eta_{\text {cata }}\right)$ 
can thus expressed as a Wiebe function of AFR according to Shaw's approach in [8] (see Fig. 3). The tailpipe mass flow for each pollutant is then given by (9).

$$
\dot{m}_{S}=\dot{m}_{f} \cdot\left(1+\frac{\psi_{S}}{\phi}\right) \cdot[S](\phi) \cdot\left(1-\eta_{c a t a}(\phi)\right)
$$

\section{Optimization Method}

\section{A. Optimal control problem}

Ecodriving consists in optimizing gear choice and velocity trajectory for a given trip. We have applied the algorithm developed by Mensing during her PhD studies [9]. Gear choice is the result of an instantaneous optimization: the gear which results in the lowest cost is chosen for each time-step. On the other hand, acceleration is the controllable input to be optimized. This can be formulated as an optimal control problem where acceleration is the control variable $(u(t)=a(t))$.

The state vector of the system $(x)$ can be described by two variables: speed and distance $(x(t)=[v(t), d(t)])$ which are submitted to the dynamics given by (10).

$$
\left[\begin{array}{c}
\dot{v}(t) \\
\dot{d}(t)
\end{array}\right]=\left[\begin{array}{ll}
0 & 0 \\
1 & 0
\end{array}\right]\left[\begin{array}{l}
v(t) \\
d(t)
\end{array}\right]+\left[\begin{array}{l}
1 \\
0
\end{array}\right] a(t)
$$

In order to study pollutant emissions and fuel consumption, the cost function to be minimized is a weighted sum of both during a time window $(T)$. Equations (1) to (9) define consumption and pollutant mass flows as a function of the control variable and state vector, the objective function can thus be written as (11). In order to compare the various pollutants, the corresponding Euro 4 emission limit $\left(S_{\text {lim }}\right)$ are introduced as a scaling factor.

$$
J=\int_{0}^{T}\left(\dot{m}_{f}(u(t), x(t))+\alpha \sum_{S} \frac{\dot{m}_{S}(u(t), x(t))}{S_{l i m}}\right) d t
$$

The problem's constraints describe the predetermined trip. They consist of speed limits, initial and final velocity, as well as total trip distance and time. The maximum allowable speed is given as a function of distance.

This optimization is usually performed using dynamic programming or the Pontryagin Minimum Principle [10]. We used dynamic programming, which can be computation intensive but allows an easier integration of constraints.

This ecodriving method was introduced by Hooker in [11] and it is based on the iterative solving of a graph built by discretizing the vehicle's state variables. In order to account for the constraints in time, distance and speed, Hooker used a 3-dimensional approach with time as one of the three state variables. However, further developments in [12], [9], and [10] chose only two state variables (distance and velocity) and included the time constraint in the objective function in order to speed up calculation. As we chose the same approach, the discrete-time objective function is given by (12) where $\Delta t_{k}$ is a variable time-step.

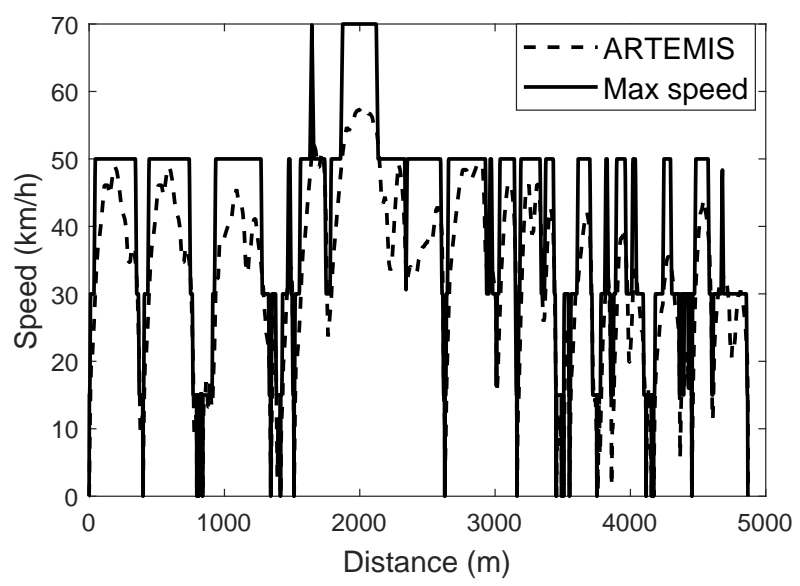

Fig. 4. Speed constraints extrapolated form ARTEMIS urban cycle

$$
\begin{aligned}
J= & \sum_{k} \dot{m}_{f, k} \Delta t_{k} \\
& +\alpha \cdot \sum_{k}\left(\frac{\dot{m}_{C O, k}}{C O_{l i m}}+\frac{\dot{m}_{H C, k}}{H C_{l i m}}+\frac{\dot{m}_{N O x, k}}{N O x_{l i m}}\right) \Delta t_{k} \\
& +\beta \cdot \sum_{k} \Delta t_{k}
\end{aligned}
$$

The trade-off between fuel consumption and pollution is investigated by varying the weighting factor $\alpha$. For each value of $\alpha$, the parameter $\beta$ is determined with a bisection method in order to fulfill the time constraint.

\begin{tabular}{|c|c|}
\hline Mass & $1470 \mathrm{~kg}$ \\
\hline Gearbox & 5-speed (38/11 28/15 40/31 39/41 35/47) \\
\hline Final drive & $81 / 17$ \\
\hline Catalyst & three-way catalytic converter (EURO 4) \\
\hline Engine & 1.6L naturally aspired gasoline indirect injection \\
\hline
\end{tabular}

\section{B. Simulation parameters}

Our vehicle model is based on a Peugeot 308, with typical values for a compact car :

TABLE I

VEHICLE SPECIFICATIONS

The main results of this study are presented with speed constraints extrapolated from the urban driving cycle of the ARTEMIS program (see Fig. 4). The total trip time for the optimization is only 710 seconds as idle periods have been cut (their speed profile is already fixed). The corresponding fuel consumption and emissions are added after the graph has been solved.

As highlighted in [10], the results of dynamic programming depend on the state variables' discretization step. We have chosen a distance step of 2 meters and a speed step of 0.01 meters per second, as further refining didn't have a significant impact on the results. 


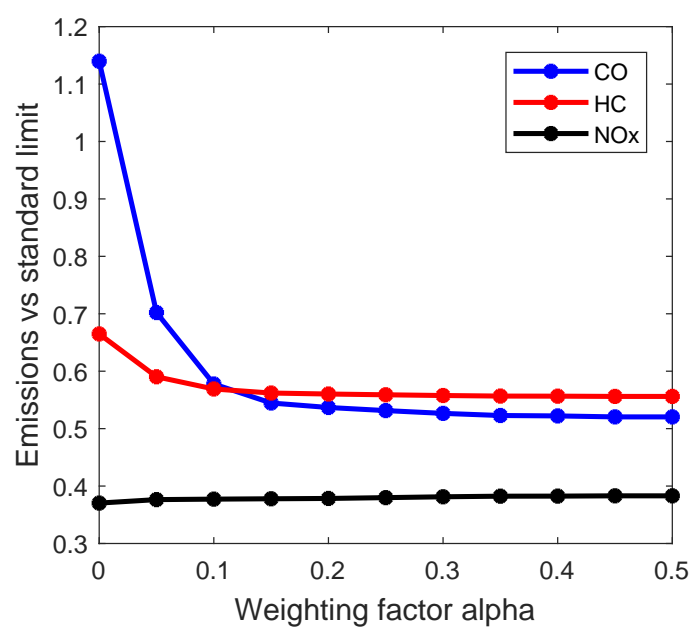

Fig. 5. Emission ratios as a function of weighting factor $\alpha$

\section{RESULTS AND DISCUSSION}

\section{A. Simulated emissions}

While the simulated speed profile does not match the standard (New European Driving Cycle), we could have expected emissions similar or higher than the limit as our cycle is quite dynamic. However, for all the tested scenarios (pollutant weighting factor $\alpha \in[0,0.5])$, simulated $\mathrm{HC}$ are lower than the limit and NOx emissions are significantly lower than the associated standard (see Fig. 5). This is consistent with the fact that our emissions model does not account for the coldstart period where the catalyst efficiency is close to null. The impact of this phase can be great in the case of $\mathrm{HC}$, as mentioned in [13]. On the other hand, CO levels are the closest to the limit, which suggests that the model offers a better description of $\mathrm{CO}$ formation mechanisms. This matches with Andrianov's observations [14] that CO concentrations are weakly dependent on all tested variables other than AFR.

$\mathrm{CO}$ and $\mathrm{HC}$ are mainly emitted during short acceleration bursts as a series of spikes (see Fig. 6) which correspond to high-load fuel-rich operation. In our model, these phases have a very adverse effect on $\mathrm{CO}$ and $\mathrm{HC}$ as high exhaust concentrations coincide with low catalyst efficiency. Recent measurements by Zhu [15] show that while AFR has a lesser effect on $\mathrm{HC}$ emissions, $\mathrm{CO}$ is indeed emitted in short spikes which match fuel-rich operation.

\section{B. Emissions vs consumption}

In our emissions model, the choice of a weighted objective function has a significant impact on emissions. While fuel consumption stays stable (see table II), HC and CO sharply decrease and reach an asymptotic value with the increase of the weighting factor $\alpha$ (see Fig. 5). The NOx emissions slightly increase as their behavior is antagonistic with regards to the AFR but they stay significantly below the standard value. We can compare two extreme scenarios.
TABLE II

FUEL-CENTERED AND POLL.-CENTERED SCENARIOS COMPARED

\begin{tabular}{ccccc}
\hline & Fuel $(\mathrm{L} / 100 \mathrm{~km})$ & $\mathrm{CO}(\mathrm{g} / \mathrm{km})$ & $\mathrm{HC}(\mathrm{g} / \mathrm{km})$ & $\mathrm{NOx}(\mathrm{g} / \mathrm{km})$ \\
\hline Fuel-cent. & 5.8 & 1.1 & 0.07 & 0.03 \\
\hline Poll-cent. & $+0.1 \%$ & $-55 \%$ & $-17 \%$ & $+3 \%$ \\
\hline
\end{tabular}
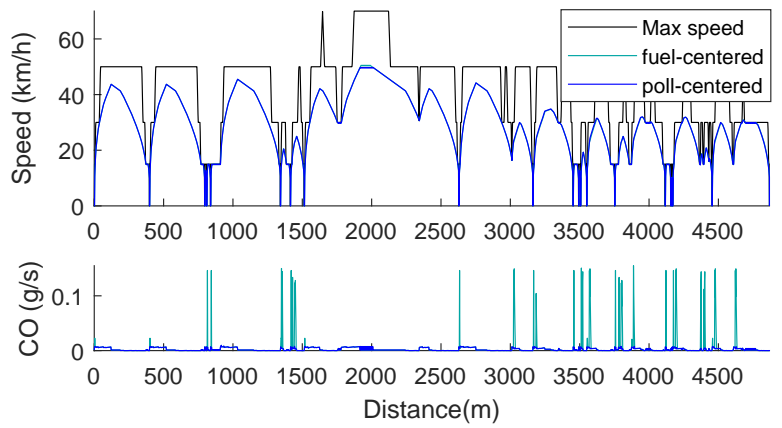

Fig. 6. Ecodriving cycles and $\mathrm{CO}$ emissions for the identified scenarios

- In the fuel-centered scenario, the objective function only considers the fuel consumption $(\alpha=0)$.

- In the pollutant-centered scenario, the emission term has a high weighting factor $(\alpha>0.3)$.

It can be observed in Fig. 6 that both scenarios have almost overlapping speed profiles. They both implement the same strategy in order to reduce the fuel consumption as illustrated on Fig. 7 where we zoom on a sequence between two stops. The optimal solution alternates between acceleration phases ( $\mathrm{P} 1$ in white), stabilized speed ( $\mathrm{P} 2$ in yellow), slow deceleration (P3 in blue) and fast deceleration (P4 in green).

In the acceleration phases (P1), high gears are chosen in order to increase the torque (and lower the engine speed) to take advantage of the increase in efficiency of the engine in higher torque regions. In the slow deceleration phases (P2), the engine is disconnected from the wheels and the vehicle's speed is a result of its inertia. The engine consumes some fuel to maintain its slowest speed but the ratio between average velocity and fuel consumption is still advantageous. In the fast deceleration phases (P3), the engine is connected to the wheels and functions as a brake. The injection is then cutoff and there is no fuel consumption. Finally, the stabilized speed phases (P4) actually show an oscillating behavior around a mean speed by alternating between acceleration and slow deceleration. The resulting fuel consumption is lower than maintaining the equivalent cruising speed by taking full advantage of the engine efficiency and of the vehicle's inertia.

This last strategy leads to very frequent disengaging of the engine which is not very realistic and the oscillating behavior might be uncomfortable for the user. A more realistic driving style could be proposed by grouping all the decelerating phases and all the accelerating phases together. The optimality of this solution could be investigated by introducing a penalty for frequent gear change in the current algorithm. 

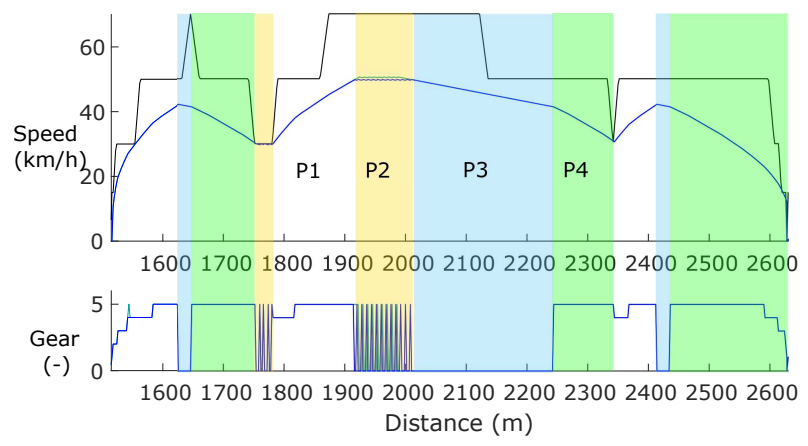

Fig. 7. Analysis of the strategy to reduce fuel consumption

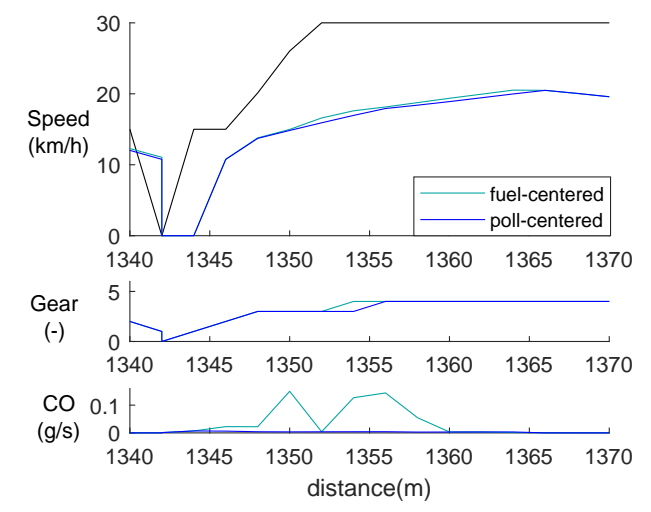

Fig. 8. Analysis of the strategy to reduce pollutant emissions

While excursions in the fuel-rich zone still occur for the pollutant-centered scenario in the dynamic phases in order to meet the time constraint, the decrease in $\mathrm{CO}$ and $\mathrm{HC}$ is obtained by reducing the load. In the fuel-centered scenario, the maximum load is very close to $100 \%$ (99.9\%). In the pollutant-centered scenario, the load does not exceed $87 \%$ of the highest torque ( $85 \%$ being the start of the fuel-rich zone).

This is achieved thanks to a change in acceleration and gear shifting strategy for the acceleration phases. Such a behavior is shown in Fig. 8 where we zoom on a dynamic phase. The pollutant-centered scenario displays a lower acceleration (lower resulting speed) and the choice of a higher gear is delayed in order to keep the torque within acceptable bounds. This strategy successfully reduces the CO spike.

While the $\mathrm{CO}$ and $\mathrm{HC}$ emissions are significantly reduced, the fuel consumption stays stable. This suggest that several paths lead to a similar fuel consumption with different acceleration strategies, which introduces a degree of freedom to optimize the emissions.

Finally, NOx emissions increase by $3 \%$ in the pollutantcentered scenario. This is not surprising as NOx formation mechanisms requires high temperatures [6] and fuel in excess lowers it. Furthermore, while $\mathrm{CO}$ and $\mathrm{HC}$ oxidation in the catalyst is less efficient in rich conditions, NOx reduction is improved. The effect of AFR on NOx is thus inconsistent with the one it has on the other species.
TABLE III

FUEL CONSUMPTION AND EMISSIONS FOR VARIOUS ARRIVAL TIMES

\begin{tabular}{cccc}
\hline & $\mathrm{T}$ & $0.9 \mathrm{~T}$ & $0.8 \mathrm{~T}$ \\
\hline Fuel $(\mathrm{L} / 100 \mathrm{~km})$ & 5.8 & 6.4 & 8.2 \\
\hline $\mathrm{CO}(\mathrm{g} / \mathrm{km})$ & 0.5 & 0.6 & 0.8 \\
\hline $\mathrm{HC}(\mathrm{g} / \mathrm{km})$ & 0.06 & 0.06 & 0.08 \\
\hline NOx $(\mathrm{g} / \mathrm{km})$ & 0.03 & 0.02 & 0.03 \\
\hline
\end{tabular}

TABLE IV

RELATIVE DIFF. BETWEEN SCENARIOS FOR VARIOUS ARRIVAL TIMES

\begin{tabular}{cccc}
\hline & $\mathrm{T}$ & $0.9 \mathrm{~T}$ & $0.8 \mathrm{~T}$ \\
\hline Fuel $(\mathrm{L} / 100 \mathrm{~km})$ & $+0.1 \%$ & $+0.3 \%$ & $+1.6 \%$ \\
\hline $\mathrm{CO}(\mathrm{g} / \mathrm{km})$ & $-55 \%$ & $-18 \%$ & $-96 \%$ \\
\hline $\mathrm{HC}(\mathrm{g} / \mathrm{km})$ & $-16 \%$ & $-2 \%$ & $-79 \%$ \\
\hline $\mathrm{NOx}(\mathrm{g} / \mathrm{km})$ & $+3 \%$ & $-25 \%$ & $+44 \%$ \\
\hline
\end{tabular}

\section{Effect of trip constraints}

In order to validate the previous results on several missions, we will study the impact of the trip's arrival time and the chosen cycle on fuel consumption and pollutant emissions in the following sections.

Table III shows the emissions and pollution results for the pollutant-centered scenario, when the total trip time is reduced by $10 \%$ and by $20 \%$. Table IV corresponds to the relative difference between the pollutant-centered and the fuel-centered scenario for each arrival time.

In table III, we observe that the consumption increases when the trip time is shorter, as expected. This trade-off between arrival time and consumption has already been studied in literature [16] [9]. Table IV shows that for all trip times, the consumption increases for the pollutant-centered scenario. The increase is more substantial for a reduced trip time as there is less freedom to choose the speed profile. However, the maximum fuel consumption increase that we have observed is still less than $2 \%$ which is relatively stable.

Table III displays an increase in $\mathrm{CO}$ as the travel time decreases. This is due to increasingly dynamic phases which require high loads and fuel in excess. The impact of travel time on $\mathrm{HC}$ is less pronounced but the same trends still hold. A trade-off between emissions and travel time is thus revealed, as previously described with fuel consumption. In table IV, there is always a significant decrease in $\mathrm{CO}$ between the pollutant-centered scenario and the fuel-centered scenario. This is expected as $\mathrm{CO}$ emissions are the closest to the standard limit and thus have the largest impact on the sum of normalized emissions. Minimizing the pollution term is thus closely related to the minimization of $\mathrm{CO}$ emissions. As mentioned earlier, $\mathrm{HC}$ emissions present a behavior similar to that of $\mathrm{CO}$, with a less pronounced impact as the decrease in catalyst efficiency for CO is significantly steeper (Fig. 3).

The response of NOx emissions to AFR is inconsistent with the one it has on CO and HC. Furthermore, the modeled emissions for this pollutant are low, which makes the relative differences quite sensitive to even small changes in values. 
TABLE V

FUEL CONSUMPTION AND EMISSIONS FOR VARIOUS DRIVING CYCLES

\begin{tabular}{cccc}
\hline & ARTURB & ARTROUT & HYZURB \\
\hline Fuel $(\mathrm{L} / 100 \mathrm{~km})$ & 5.8 & 3.9 & 5.1 \\
\hline $\mathrm{CO}(\mathrm{g} / \mathrm{km})$ & 0.5 & 0.2 & 0.4 \\
\hline $\mathrm{HC}(\mathrm{g} / \mathrm{km})$ & 0.06 & 0.03 & 0.05 \\
\hline NOx $(\mathrm{g} / \mathrm{km})$ & 0.03 & 0.01 & 0.02 \\
\hline
\end{tabular}

TABLE VI

RELATIVE DIFF. BETWEEN SCENARIOS FOR VARIOUS DRIVING CYCLES

\begin{tabular}{cccc}
\hline & ARTURB & ARTROUT & HYZURB \\
\hline Fuel $(\mathrm{L} / 100 \mathrm{~km})$ & $+0.1 \%$ & $+0.1 \%$ & $+0.2 \%$ \\
\hline $\mathrm{CO}(\mathrm{g} / \mathrm{km})$ & $-55 \%$ & $-40 \%$ & $-34 \%$ \\
\hline $\mathrm{HC}(\mathrm{g} / \mathrm{km})$ & $-16 \%$ & $-10 \%$ & $-8 \%$ \\
\hline $\mathrm{NOx}(\mathrm{g} / \mathrm{km})$ & $+3 \%$ & $-0.2 \%$ & $+3 \%$ \\
\hline
\end{tabular}

A trade-off between emissions and consumption for this particular pollutant is not observed for the arrival times that we studied (see table III). A more complete model would need to be built in order to conclude as to the trends for this pollutant as it depends on a large number of other parameters, such as spark timing, engine speed, and intake conditions [14].

Table $\mathrm{V}$ shows the emissions and pollution results for the pollutant-centered scenario, for the previously introduced urban ARTEMIS cycle (ARTURB), the extra-urban ARTEMIS cycle (ARTROUT) and the urban hyzem cycle (HYZURB). Table VI corresponds to the relative difference between the pollutant-centered and the fuel-centered scenario for each driving cycle. It can be observed that the results are very similar for each driving cycle, with a significant impact on HC and $\mathrm{CO}$ while consumption and NOx stay relatively stable.

\section{CONCLUSion}

This paper discusses the trade-off between pollutant emissions and fuel consumption in ecodriving for gasoline engines, which is affected by the torque management.

Ecodriving cycles can involve high loads as they allow the driver to satisfy the travel time constraint with little decrease in the engine efficiency. However, they can lead to higher $\mathrm{CO}$ and $\mathrm{HC}$ emissions as they are associated to fuel-rich combustion. In order to predict and minimize pollutant emissions, we introduced a simplified model describing the effect of air/fuel ratio on tailpipe emissions.

Its use in a weighted objective function to solve the ecodriving problem with dynamic programming allowed us to identify a fuel-centered and a pollutant-centered scenario. The latter showed great potential for emissions reduction with a relative decrease as high as $55 \%$ for $\mathrm{CO}$ and $16 \%$ for $\mathrm{HC}$ while fuel consumption stayed stable. Pollutant emissions decreased thanks to a change in acceleration and gear shifting strategy in the dynamic phases which resulted in lower engine torques. Small excursions in the fuel-rich zone still occurred especially in the case of shorter travel times, resulting in a trade-off between trip time and pollutant emissions.
Further work will focus on refining the emissions model to account for the influence of other parameters such as power demand, spark timing and intake conditions on $\mathrm{HC}$ and NOx concentrations. The dynamics of the air/fuel ratio can also be studied by modeling the oxygen storage in the catalyst or fuel pooling in the intake manifold (indirect injection). This work could also be extended to take the cold start period into account in order to optimize the light-off of the catalytic converter in the context of pollutant-centered ecodriving.

This approach could also be applied to hybrid electric vehicles, with an additional degree of freedom concerning the torque split between the electric machine and the internal combustion engine. This involves adding an additional dimension in the dynamic programing graph, leading to a complex and computation intensive resolution. In this context, a Hamiltonian formulation might be more appropriate, as long as the expression of the various adjoint states can be derived.

\section{REFERENCES}

[1] J. B. Heywood, Internal Combustion Engine Fundamentals. McGrawHill, 1988.

[2] E. Ericsson, "Independent driving pattern factors and their influence on fuel-use and exhaust emission factors," Transportation Research Part D, vol. 6 (5), pp. 325-345, 2001.

[3] F. Mensing, E. Bideaux, R. Trigui, J. Ribet, and B. Jeanneret, "Ecodriving: an economic or ecologic driving style?" Transportation Research Part C, vol. 38, pp. 110-121, 2014.

[4] H. Johansson, J. Farnlund, and C. Engstrom, "Impact of ecodriving on emissions and fuel consumption, a pre-study," Swedish National Road Administration, Tech. Rep., 1999.

[5] A. Kean, R. Harley, and G. Kendall, "Effects of vehicle speed and engine load on motor vehicle emissions," Environmental science \& technology, vol. 37 (17), pp. 3739-3746, 2003.

[6] L. Guzzella and C. H. Onder, Introduction to Modeling and Control of Internal Combustion Engine Systems. Springer, 2004.

[7] E. Vinot and B. Jeanneret, "Fuel consumption vs pollutant emission trade-off for hybrid electric vehicle. an application of the pontryagins minimum principle." in Vehicle Power and Propulsion Conference (VPPC), 2014.

[8] B. T. Shaw, G. D. Fischer, and J. K. Hedrick, "A simplified coldstart catalyst thermal model to reduce hydrocarbon emissions," in IFAC World Congress, 2002.

[9] F. Mensing, "Optimal energy utilization in conventional, electric and hybrid vehicles and its application to eco-driving," Ph.D. dissertation, INSA de Lyon, 2013.

[10] D. Maamria, K. Gillet, G. Colin, Y. Chamaillard, and C. Nouillant, "Which methodology is more appropriate to solve eco-driving optimal control problem for conventional vehicles," in IEEE Conference on Control Applications, 2016.

[11] J. Hooker, "Optimal driving for single-vehicle fuel economy," Transportation Research, pp. 183-201, 1988.

[12] V. Monastyrsky and I. Golownykh, "Rapid computation of optimal control for vehicles," Transportation Research, vol. 27, p. 219227, 1993.

[13] B. T. Shaw and J. K. Hedrick, "Coldstart engine combustion modelling to control hydrocarbon emissions," in IFAC World Congress, 2002.

[14] D. I. Andrianov, M. J. Brear, and C. Manzie, "A physics-based integrated model of a spark ignition engine and a three-way catalyst," Combustion Science and Technology, vol. 184 (9), pp. 1269-1301, 2012.

[15] G. Zhu, J. Liu, J. Fu, Z. Xu, Q. Guoc, and H. Zhao, "Experimental study on combustion and emission characteristics of turbocharged gasoline direct injection (gdi) engine under cold start new european driving cycle (nedc)," Fuel, vol. 215, pp. 272-284, 2018.

[16] S. Javanmardi, E. Bideaux, R. Trigui, E. Nicouleau-Bourles, S. Dehoux, and H. Mathieu, "Effect of trajectory optimization parameters on energy consumption and co2 emissions for a gasoline powered vehicle," Journal of Earth Sciences and Geotechnical Engineering, vol. 7 (1), pp. $263-$ 276, 2017. 